\title{
The protective effect of dexmedetomidine in a rat ex vivo lung model of ischemia-reperfusion injury ${ }^{1}$
}

Yan Zhou', Xinqiao Zhou", Wenjuan Zhou"', Qingfeng Pang "' , Zhiping Wang ${ }^{v}$

'MD, Attending physician, Department of Anesthesiology, Affiliated Wuxi People's Hospital, Nanjing Medical University, China. Acquisiton, analysis and interpretaton of data; manuscript preparation.

"MD, Resident, Department of Anesthesiology, Affiliated Wuxi People's Hospital, Nanjing Medical University, China. Technical procedures, acquisition of data.

I'MD, Resident, Department of Anesthesiology, Affiliated Wuxi People's Hospital, Nanjing Medical University, China. Technical procedures.

IVPhD, Full Professor, Department of Basic Medicine, Wuxi Medical School, Jiangnan University, China. Technical procedures.

vPhD, Full Professor, Department of Anesthesiology, Affiliated Wuxi People's Hospital, Nanjing Medical University, China. Conception and design of the study, manuscript preparation, final approval.

\begin{abstract}
Purpose: To investigate the effect of dexmedetomidine (Dex) in a rat ex vivo lung model of ischemia-reperfusion injury.

Methods: An IL-2 ex vivo lung perfusion system was used to establish a rat ex vivo lung model of ischemia-reperfusion injury. Drugs were added to the perfusion solution for reperfusion. Lung injury was assessed by histopathological changes, airway pressure (Res), lung compliance (Compl), perfusion flow (Flow), pulmonary venous oxygen partial pressure $\left(\mathrm{PaO}_{2}\right)$, and lung wet/dry (W/D) weight ratio. The levels of superoxide dismutase (SOD), malondialdehyde (MDA), $78 \mathrm{kDa}$ glucose-regulated protein (GRP78) and CCAAT/enhancer-binding protein homologous protein (CHOP) were measured, respectively.

Results: The introduction of Dex attenuated the post-ischemia-reperfusion lung damage and MDA level, improved lung histology, W/D ratio, lung injury scores and SOD activity. Decreased mRNA and protein levels of GRP78 and CHOP compared with the IR group were observed after Dex treatment. The effect of Dex was dosage-dependence and a high dose of Dex (10 $\mathrm{nM})$ was shown to confer the strongest protective effect against lung damage $(\mathrm{P}<0.05)$. Yohimbine, an $\alpha_{2}$ receptor antagonist, significantly reversed the protective effect of Dex in lung tissues $(P<0.05)$.
\end{abstract}

Conclusion: Dex reduced ischemia-reperfusion injury in rat ex vivo lungs.

Key words: Dexmedetomidine. Reperfusion Injury. Ischemia. Lung. Rats. 


\section{Introduction}

Lung transplant is the standard treatment for end-stage lung diseases ${ }^{1}$. However, it is often complicated by high incidence of lung ischemia-reperfusion injury (LIRI), resulting in morbidity and mortality in lung or heart-lung transplantation ${ }^{2}$. LIRI may cause primary graft dysfunction, which is one of the main factors affecting the short- and long-term survival after lung transplant ${ }^{3,4}$. Researchers have been studying ways to attenuate or ameliorate ischemia-reperfusion injury; however, the mechanisms leading to LIRI are not fully understood ${ }^{5}$.

Dexmedetomidine (Dex), a highly selective $\alpha_{2}$ adrenergic receptor agonist, has sedative, analgesic, anti-sympathetic, and circulation stabilizing effects, with little or no respiratory repression. It is widely used for perioperative anesthesia and sedation ${ }^{6}$. Dex has been found to have protective effects on ischemia-reperfusion injury in multiple organs, including heart, liver, brain, kidney, and intestine, as well as on LPS-induced acute lung injury ${ }^{7}$. Previous studies have shown that Dex inhibited malondialdehyde (MDA) production in the spinal cord during early reperfusion, thus reducing inflammation and ischemiareperfusion injury ${ }^{8}$. In lung, Dex has been reported to significantly reduce the pulmonary inflammation in ventilator-induced lung injury in a rat model $^{9}$, and was capable of protecting lung from acute ischemia-reperfusion injury by inhibiting the production of proinflammatory cytokines correlated with LIRI ${ }^{10}$.

LIRI has also been associated with oxidative stress, autoimmune response, and endothelial barrier injury ${ }^{11}$. Findings from recent studies have suggested that unfolded protein response (UPR) induced by excessive endoplasmic reticulum stress (ERS) may be an important pathophysiological mechanism of LIRI ${ }^{12}$. Under non-stress conditions, ERS receptors are maintained in an inactive state through binding of $78 \mathrm{kDa}$ glucose regulated protein (GRP78, also known as BiP) ${ }^{13}$. Upon accumulation of unfolded proteins, dissociation of GRP78 from the receptors leads to activation of the ERS receptors, thereby inducing the UPR. UPR consists of a cascade of downstream events resulting in the protein synthesis attenuation, activation of protein degradation, and the induction of ER luminal chaperones, such as GRP78 and GRP94, to promote protein folding ${ }^{13,14}$. These events in turn promote a pro-survival signaling pathway by regulating ER homeostasis ${ }^{14}$. However, during conditions of prolonged ERS, pro-survival response fails and apoptotic pathway is activated through the CCAAT/enhancer-binding protein homologous protein (CHOP)-mediated induction of proapoptotic genes and suppression of antiapoptotic protein synthesis ${ }^{13,14}$.

The expression of CHOP is maintained at low level under non-stressed conditions; however, when UPR is activated, CHOP expression markedly increases, which in turn activates apoptosis ${ }^{13}$. Interestingly, CHOP is not only involved in apoptosis, but has also been shown to play a role in inflammatory responses. Treatment with lipopolysaccharide (LPS) activates expression of CHOP in mouse lungs ${ }^{15}$, which has been shown to play a crucial role in activating caspase-11, a cascade event involved in the secretion of IL-1 $\beta^{16}$.

Studies of LIRI have been performed using an in situ lung ischemia-reperfusion model ${ }^{17}$. However, this approach has its drawbacks, such as incomplete observation indexes, the presence of confounding factors, and unsatisfactory simulation of the normal physiological breathing pattern with mechanical ventilation. To overcome the disadvantages of the aforementioned model, the IL-2 system has been introduced, which is the most advanced platform currently available for research on ex vivo lung transplant and different respiratory diseases. The IL-2 system simulates in vivo lung environment and enables continuous and consistent monitoring of the Res, Compl, Flow, $\mathrm{pH}$, and $\mathrm{PaO}_{2}$ of the ex vivo lung ${ }^{18,19}$. 
More importantly, the IL-2 system has been shown to recapitulate the histopathological changes caused by ischemia-reperfusion (IR), proving it a useful LIRI model ${ }^{18,19}$. Although Dex has been shown to significantly protect against LIRI by reducing the expression of inflammatory molecules including TNF- $\alpha$ (tumor necrosis factor- $\alpha$ ), IL-6 (interleukin-6), MCP-1 (monocyte chemoattractant protein-1), and negatively regulated the expression of TLR4 (toll-like receptor 4) and the activation of inflammation signaling pathways such as JNK (c-Jun terminal kinase) and ERK1/2 (extracellular-signal regulated kinase $1 / 2)^{10}$, the effects of Dex on the ERS-related components such as CHOP and GRP78 are yet to be elucidated. We therefore hypothesized that Dex may have protective effects against LIRI through regulating ERS homeostasis. Thus, in this study, we established a rat ex vivo lung model of IR injury to determine the effects of Dex on LIRI by investigating the expression of ERS-related components.

\section{- Methods}

\section{Establishment of the rat model}

All animal experiments were complied with the ARRIVE guidelines and should be carried out in accordance with the U.K. Animals (Scientific Procedures) Act, 1986 and associated guidelines, EU Directive 2010/63/ EU for animal experiments, or the National Institutes of Health guide for the care and use of Laboratory animals (NIH Publications no 8023, revised 1978).

A modified rat ex vivo lung model of IR injury was established according to PegoFernandeset al. ${ }^{18,20}$ as follows: $0.1 \mathrm{mg}$ of atropine was intraperitoneally injected, followed by intraperitoneal injection of 3\% pentobarbital sodium (50 $\mu \mathrm{g} / \mathrm{g}$ ) after 10 minutes. An incision was made along the neck midline, a tracheal tube was placed, and a ventilator designed for small animals was connected to maintain breathing (inhalation oxygen $\left[\mathrm{FiO}_{2}\right]$ : $21 \%$, tidal volume [VT]: $10 \mathrm{ml} / \mathrm{kg}$, frequency: 71 tpm, inspiratory to expiratory ratio: 1:2). After the chest was opened along the midline, the trunk of the pulmonary artery was separated, and a \#1 suture was placed (without ligation). Heparin sodium $(1.000 \mathrm{U} / \mathrm{kg}$ ) was injected into the left ventricle, a transverse incision was made in the right ventricle, and a catheter was inserted into the right ventricle and advanced into the trunk of the pulmonary artery, which was then ligated and secured. A longitudinal incision was made in the left ventricle (near the apex); a catheter was inserted via the opening of the left ventricle into the left atrium; a \#1 suture was used to ligate the opening of the left ventricle, along with the catheter, to form a closed loop to infuse optimized Krebs-Henseleit solution into the pulmonary artery. This perfusion solution contained 4.7 $\mathrm{mM}$ potassium chloride, $2.51 \mathrm{mM}$ calcium chloride, $1.19 \mathrm{mM}$ magnesium sulfate, $2.5 \mathrm{mM}$ potassium dihydrogen phosphate, $118 \mathrm{mM}$ sodium chloride, $25 \mathrm{mM}$ sodium bicarbonate, $5.5 \mathrm{mM}$ glucose, and $3 \%$ bovine serum albumin. The lungs were quickly isolated and placed into the negative pressure chamber of the IL-2 ex vivo lung perfusion system (Harvard Apparatus, Holliston, Mass, United States); the ventilation mode was switched to negative pressure ventilation. The perfusion solution in the system was maintained at $37^{\circ} \mathrm{C}, \mathrm{pH} 7.35$ 7.45 , and a constant pressure of $10 \mathrm{cmH}_{2} \mathrm{O}$. Air was used for ventilation. After 15 minutes in the system, ventilation and perfusion were stopped and resumed after 60 minutes for 75 minutes.

\section{Experimental animals and group assignment}

This study is in compliance with the regulation of the US National Institute of Health (NIH) Guide for the Care and Use of Laboratory Animals.

A total of 56 healthy SPF-grade male SD 
rats (250-320g) were purchased from Shanghai SLAC Experiment Animal Co. Ltd. and housed at $22-25^{\circ} \mathrm{C}$ and $55 \%-60 \%$ relative humidity, with free access to food and water. A randomization number sheet was used to divide the SD rats into seven groups ( $n=8$ per group) as follows: $i$ ) control group (S group), $2 \mathrm{ml}$ saline treatment; ii) ischemia-reperfusion group (IR group), $2 \mathrm{ml}$ saline treatment; iii) low-dose $1 \mathrm{nM}$ Dex group (D1 group); iv) intermediate-dose $5 \mathrm{nM}$ Dex group (D5 group); v) high-dose $10 \mathrm{nM}$ Dex group (D10 group); vi) $10 \mathrm{nM}$ Dex and $1 \mu \mathrm{M}$ yohimbine group (DY group); and vii) $1 \mu \mathrm{M}$ yohimbine group (Y group). The $S$ group was placed in the IL-2 ex vivo lung perfusion system, and normal lung ventilation and perfusion was maintained for 150 minutes. The IR group was used to establish the rat ex vivo lung model with IR injury as described above. Dex (batch number: 15123132, Jiangsu Hengrui Medicine Co. Ltd.) and/or yohimbine, an $\alpha_{2}$ adrenergic receptor blocker (batch number: Y3215-1G, Sigma, USA) were added to the ex vivo perfusion solution at the beginning of reperfusion.

\section{Ex vivo lung function}

In the ex vivo lung perfusion system, the airway pressure (Res), lung compliance (Compl), perfusion flow (flow), and $\mathrm{PaO}_{2}$ were measured using the IL-2 system and were recorded at the following timepoints: 10 minutes after the initial perfusion (T0), and 15 minutes (T1), 45 minutes (T2), and 75 minutes (T3) after reperfusion.

\section{Lung wet/dry (W/D) weight ratio}

In each group, approximately $0.5 \mathrm{~g}$ of fresh tissue from the same location of the left upper lobe was removed, washed with phosphate-buffered saline, dabbed dry with filter paper, and immediately weighed to obtain the wet weight. Next, the tissue was dried in a $45^{\circ} \mathrm{C}$ electric thermostatic drying oven for 72 hours and was weighed following desiccation (when the weight had become constant) to obtain the dry weight. The lung water content was assessed by the W/D ratio.

\section{Lung injury score}

A tissue sample was removed from the left lower lobe, fixed in $10 \%$ formalin for 48 hours, dewaxed, embedded, sectioned, and stained with hematoxylin and eosin and examined under a light microscope to evaluate the lung injury. The lung injury was rated according to four indexes: pulmonary interstitial edema, alveolar edema, neutrophil infiltration, and intra-alveolar congestion. The rating scale was as follows: $0=$ no change or very minor changes; $1=$ mild changes; $2=$ moderate changes; 3 = severe changes; and 4 $=$ very severe changes. The total scores of the four indexes were then summed to obtain the final lung injury score ${ }^{21}$.

\section{MDA content and SOD activity}

A tissue sample was removed from the right lower lobe, cut into smaller pieces of approximately $80 \mathrm{mg}$, snap-frozen in liquid nitrogen, and stored at $-80^{\circ} \mathrm{C}$ until use. The frozen lung tissue was removed from the freezer, weighed, and evaluated for superoxide dismutase (SOD) activity using a pyrogallol assay (Nanjing Jiancheng Bioengineering Institute) and malondialdehyde (MDA) level using a thiobarbituric acid assay (Nanjing Jiancheng Bioengineering Institute), according to the manufacturer's instructions.

\section{Quantitative PCR (qPCR) assay}

Total RNA sample was extracted from a tissue sample of approximately $80 \mathrm{mg}$ from the right upper lobe using the TRIzol reagent (Invitrogen, USA). Approximately $10 \mu \mathrm{g}$ of RNA was reverse transcribed into cDNA via the RT Reagent Kit and gDNA Eraser Kit (Takara, Japan), according to the manufacturer's instructions. The mRNA levels of GRP78 and CHOP were then analyzed by qPCR using the 
SYBR $^{\oplus}$ Green I qPCR kit (Takara, Japan) on an ABI 7500 Real-Time PCR System (ABI, USA), according to the manufacturer's instructions. $\beta$-actin, a housekeeping gene, was used as the internal control. The primers for $\beta$-actin are forward: 5'-CTGTGTGGATTGGTGGCTCT-3' and reverse: 5'-CAGCTCAGTAACAGTCCGCC-3'; for GRP78, forward: 5'-TCAGCCCACCGTAACAATCAAG-3' and reverse: 5'-TCCATCAGATCAAATGTACCAGA-3'; for CHOP, forward: 5'-TGGAAGCCTGGTATGAGGATCTG-3' and reverse: 5'- GAGGTGCTTGTGACCTCTGCTG-3'. The expression levels of CHOP and GRP78 mRNA were determined by the comparative $C_{T}$ method, $2^{-\Delta \Delta C T}$ following normalization to the internal control, $\beta$-actin.

\section{Western blotting}

GRP78 and CHOP protein expression was analyzed using Western blotting. A tissue sample of approximately $100 \mathrm{mg}$ was removed from the right middle lobe and stored at $-80^{\circ} \mathrm{C}$ until use. The tissue was cut into small pieces and homogenized in RIPA tissue lysis buffer (CoWin Biosciences, China) at $0^{\circ} \mathrm{C}$. After gradient centrifugation, the supernatant was collected, and the protein concentration was determined using the bicinchoninic acid assay (CoWin Biosciences, China). Equal amount of protein samples were separated on a $10 \%$ Tris-glycine gel using sodium dodecyl sulfatepolyacrylamide gel electrophoresis (SDSPAGE). The proteins were then transferred to a polyvinylidene fluoride (PVDF) membrane (Millipore Corporation, USA), which was then washed with Tris-buffered saline with $0.1 \%$ Tween 20 (TBST) buffer (15 minutes $\times 3$ ), and blocked in $5 \%$ skim milk at room temperature on a shaker for 2 hours. Next, the membrane was washed with TBST buffer (15 minutes $\times 3$ ), incubated with mouse anti-CHOP monoclonal antibody (1:6000, Cell Signaling Technology Inc., USA) or rabbit anti-GRP78/Bip polyclonal antibody (1:1000, Eptomics Corporation, USA) on a shaker at $4^{\circ} \mathrm{C}$ overnight. It was then washed with TBST buffer (15 minutes $x$ 3), followed by incubation with goat anti-mouse IgG (CoWin Biosciences China) or goat anti-rabbit IgG (CoWin Biosciences China) secondary antibody on a shaker at room temperature for 2 hours, and washed with TBST buffer (15 minutes $x$ 3). Next, enhanced chemiluminescence (ECL) reagents (Santa Cruz, USA) were added ( $1 \mathrm{ml}$ each of solutions $A$ and $B$ ) and the membrane was exposed to a Kodak X-OMAT BT film (Kodak, USA) for an appropriate length of time. The film was then developed for $15-30 \mathrm{~s}$ and fixed for 1.5 minutes. Next, the film was analyzed with a gel imaging system (Bio-Rad, USA). The optical density (OD) was analyzed with ImageJ software (National Institutes of Health, USA). The ratio of the OD value of the target protein to that of $\alpha$-tubulin was used as the relative expression of the target protein.

\section{Statistical analysis}

SPSS V22.0 (IBM, USA) was used for the statistical analysis. Measurement data are expressed as the mean \pm standard deviation. One-way analysis of variance (ANOVA) was performed for among-group comparison of means, and repeated-measures ANOVA was performed for intragroup comparison across different time points. $\mathrm{P}<0.05$ was considered statistically significant.

\section{Results}

\section{Ex vivo lung function}

At 10 minutes after the initial perfusion (TO), the Res, Compl, Flow, and $\mathrm{PaO}_{2}$ exhibited no significant differences among the seven groups (Table 1). However, after reperfusion (at T1, T2 and T3), significant differences were observed in the Res, Compl, Flow, and $\mathrm{PaO}_{2}$ in D1, D5, D10, and IR groups compared with that of the $S$ group $(P<0.05)$, suggesting that lung ischemia-reperfusion significantly damaged ex vivo lung function. Treatment 
with Dex significantly reduced LIRI, indicated by the improved Res, Compl, Flow, and $\mathrm{PaO}_{2}$ measurements in rats of all Dex-treated groups (D1, D5, and D10 groups) compared with the
IR group $(P<0.05)$. High dose of Dex (D10) showed the strongest protective effect against LIRI. Yohimbine significantly reversed the LIRIreducing effects of Dex $(P<0.05)$ (Table 1$)$.

Table 1 - Lung function at different time points in the seven groups ( $n=8, \bar{x} \pm s)$.

\begin{tabular}{|c|c|c|c|c|}
\hline $\begin{array}{l}\text { Group } \\
\text { Res (cn }\end{array}$ & $\mathrm{T}_{0}$ & $T_{1}$ & $T_{2}$ & $T_{3}$ \\
\hline$S$ & $0.27 \pm 0.02$ & $0.29 \pm 0 .{ }^{0} 1 a$ & $0.31 \pm 0.0^{2} a$ & $0.33 \pm 0.0^{2} a$ \\
\hline IR & $0.27 \pm 0.01$ & $0.36 \pm 0.0^{2 \mathrm{a} b}$ & $0.45 \pm 0.0^{2 \mathrm{a}} \mathrm{b}$ & $0.52 \pm 0.0^{4 \mathrm{a}} \mathrm{b}$ \\
\hline D1 & $0.26 \pm 0.01$ & $0.33 \pm 0.0^{1 \mathrm{ab}} \mathrm{C}$ & $0.36 \pm 0.0^{1 \mathrm{ab}} \mathrm{c}$ & $0.46 \pm 0.0^{4 a b} c$ \\
\hline D5 & $0.27 \pm 0.02$ & $0.32 \pm 0.0^{1 \mathrm{abc}} \mathrm{d}$ & $0.34 \pm 0.0^{1 \mathrm{abc}} \mathrm{d}$ & $0.41 \pm 0.0^{2 \mathrm{abc}} \mathrm{d}$ \\
\hline D10 & $0.27 \pm 0.02$ & $0.31 \pm 0.0^{1 \mathrm{abcd}} \mathrm{e}$ & $0.33 \pm 0.0^{2 \mathrm{abcd}} \mathrm{e}$ & $0.37 \pm 0.0^{2 \mathrm{abcd}} \mathrm{e}$ \\
\hline DY & $0.27 \pm 0.01$ & $0.36 \pm 0.0^{1 \mathrm{abde} f}$ & $0.42 \pm 0.0^{3 a b d e} f$ & $0.50 \pm 0.0^{4 a b d e} f$ \\
\hline Y & $0.26 \pm 0.02$ & $0.38 \pm 0.0^{3 \mathrm{abde}} f$ & $0.44 \pm 0.0^{3 a b d e} f$ & $0.53 \pm 0.0^{4 a b d e} f$ \\
\hline \multicolumn{5}{|c|}{ Compl $\left(\mathrm{ml} / \mathrm{cmH}_{2} \mathrm{O}\right)$} \\
\hline$S$ & $0.53 \pm 0.03$ & $0.47 \pm 0.02^{\mathrm{a}}$ & $0.42 \pm 0.02^{\mathrm{a}}$ & $0.39 \pm 0.02^{\mathrm{a}}$ \\
\hline IR & $0.52 \pm 0.03$ & $0.27 \pm 0.03^{\mathrm{ab}}$ & $0.22 \pm 0.02^{\mathrm{ab}}$ & $0.14 \pm 0.03^{\mathrm{ab}}$ \\
\hline D1 & $0.53 \pm 0.03$ & $0.33 \pm 0.03^{\mathrm{abc}}$ & $0.26 \pm 0.02^{\mathrm{abc}}$ & $0.21 \pm 0.03^{\mathrm{abc}}$ \\
\hline D5 & $0.52 \pm 0.02$ & $0.36 \pm 0.03^{\mathrm{abcd}}$ & $0.31 \pm 0.02^{\mathrm{abcd}}$ & $0.25 \pm 0.03^{\mathrm{abcd}}$ \\
\hline D10 & $0.52 \pm 0.01$ & $0.40 \pm 0.03^{\text {abcde }}$ & $0.36 \pm 0.02^{\mathrm{abcde}}$ & $0.33 \pm 0.02^{\text {abcde }}$ \\
\hline DY & $0.53 \pm 0.03$ & $0.28 \pm 0.03^{\text {abdef }}$ & $0.23 \pm 0.02^{\text {abdef }}$ & $0.15 \pm 0.02^{\text {abdef }}$ \\
\hline Y & $0.51 \pm 0.01$ & $0.26 \pm 0.02^{\text {abdef }}$ & $0.21 \pm 0.02^{\text {abdef }}$ & $0.13 \pm 0.03^{\text {abdef }}$ \\
\hline \multicolumn{5}{|c|}{ Flow (ml/min) } \\
\hline$S$ & $11.1 \pm 1.0$ & $9.1 \pm 0.7^{\mathrm{a}}$ & $8.0 \pm 0.5^{\mathrm{a}}$ & $6.8 \pm 0.8^{a}$ \\
\hline IR & $11.0 \pm 0.9$ & $5.6 \pm 0.4^{\mathrm{ab}}$ & $4.9 \pm 0.6^{\mathrm{ab}}$ & $3.7 \pm 0.6^{\mathrm{ab}}$ \\
\hline D1 & $11.0 \pm 1.0$ & $6.4 \pm 0.4^{\mathrm{abc}}$ & $5.6 \pm 0.3^{a b c}$ & $4.7 \pm 0.5^{\mathrm{abc}}$ \\
\hline D5 & $11.0 \pm 0.7$ & $7.3 \pm 0.3^{\mathrm{abcd}}$ & $6.7 \pm 0.3^{\mathrm{abcd}}$ & $5.3 \pm 0.2^{\mathrm{abcd}}$ \\
\hline D10 & $10.8 \pm 0.9$ & $8.1 \pm 0.5^{\text {abcde }}$ & $7.4 \pm 0.3^{\text {abcde }}$ & $5.8 \pm 0.5^{\text {abcde }}$ \\
\hline DY & $10.8 \pm 0.8$ & $5.8 \pm 0.3^{\text {abdef }}$ & $5.0 \pm 0.4^{\text {abdef }}$ & $3.9 \pm 0.3^{\text {abdef }}$ \\
\hline Y & $11.2 \pm 0.8^{\text {abdef }}$ & $5.5 \pm 0.4^{\text {abdef }}$ & $4.8 \pm 0.3^{\text {abdef }}$ & $3.6 \pm 0.4^{\text {abdef }}$ \\
\hline \multicolumn{5}{|c|}{$\mathrm{PaO}_{2}(\mathrm{mmHg})$} \\
\hline $\mathrm{S}$ & $116 \pm 6$ & $94 \pm 6^{a}$ & $84 \pm 7^{a}$ & $74 \pm 8^{a}$ \\
\hline IR & $118 \pm 8$ & $66 \pm 5^{a b}$ & $58 \pm 5^{a b}$ & $47 \pm 6^{a b}$ \\
\hline D1 & $115 \pm 7$ & $73 \pm 4^{a b c}$ & $65 \pm 6^{a b c}$ & $58 \pm 3^{a b c}$ \\
\hline D5 & $117 \pm 6$ & $79 \pm 4^{\mathrm{abcd}}$ & $70 \pm 4^{\mathrm{abcd}}$ & $63 \pm 4^{\mathrm{abcd}}$ \\
\hline D10 & $116 \pm 7$ & $85 \pm 6^{\text {abcde }}$ & $75 \pm 3^{\text {abcde }}$ & $69 \pm 3^{\text {abcde }}$ \\
\hline DY & $115 \pm 6$ & $66 \pm 2^{\text {abdef }}$ & $58 \pm 4^{\text {abdef }}$ & $50 \pm 6^{\text {abdef }}$ \\
\hline Y & $115 \pm 7$ & $64 \pm 3^{\text {abdef }}$ & $56 \pm 3^{\text {abdef }}$ & $46 \pm 5^{\text {abdef }}$ \\
\hline
\end{tabular}

${ }^{\mathrm{a}} \mathrm{P}<0.05$ compared with $\mathrm{T}_{0} ;{ }^{\mathrm{b}} \mathrm{P}<0.05$ compared with $\mathrm{S} ;{ }^{\mathrm{C}} \mathrm{P}<0.05$ compared with $\mathrm{IR}$; ${ }^{\mathrm{d}} \mathrm{P}<0.05$ compared with $\mathrm{D} 1 ;{ }^{\text {e }} \mathrm{P}<0.05$ compared with D5; ${ }^{\mathrm{f}} \mathrm{P}<0.05$ compared with $\mathrm{D} 10$. 


\section{Lung $W / D$ ratio}

The lung W/D weight ratio was measured following reperfusion to evaluate the IR-induced lung edema. The W/D ratio was significantly increased in the IR group $(8.4 \pm 0.7)$ compared with that of the $S$ group $(5.0 \pm 0.6 ; P<0.05)$. The ratio was significantly reduced following treatment with Dex (D1 group, $7.3 \pm 0.4 ;$ D5 group, $6.7 \pm 0.4$; and D10 group, $6.2 \pm 0.3)$ compared with that of the IR group (all $P<0.05$ ) (Figure 1 ). Yohimbine treatment significantly reversed the effect of Dex on the lung W/D ratio (DY group, 8.3 \pm 0.5 ; and $Y$ group, $8.7 \pm 0.7$ ) compared with that of all Dex-treated groups (D1, D5 and D10 groups) $(P<0.05)$. There was no significant difference in the $W / D$ ratio between the Yohimbine groups (DY and $Y$ groups) and the IR group (Figure 1).

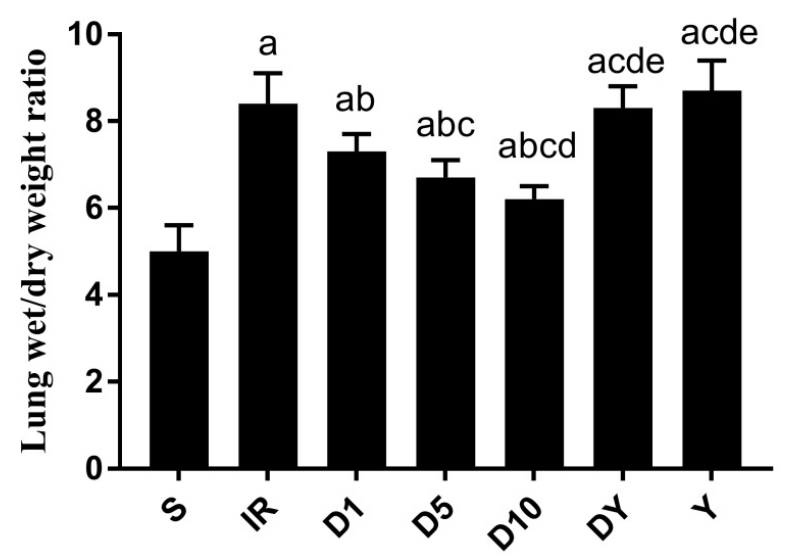

Figure 1 - Wet/dry weight ratio in lung tissues isolated from rats of the seven groups. The data are presented as the mean \pm standard deviation. S: sham; IR: ischemia-reperfusion; D1: $1 \mathrm{nM}$ dexmedetomidine; D5: 5 $\mathrm{nM}$ dexmedetomidine; D10: $10 \mathrm{nM}$ dexmedetomidine; DY: $10 \mathrm{nM}$ dexmedetomidine+1 $\mu \mathrm{M}$ yohimbine; Y: $1 \mu \mathrm{M}$ yohimbine. ${ }^{\mathrm{P}} \mathrm{P}<0.05$ compared with $\mathrm{S} ;{ }^{\mathrm{b}} \mathrm{P}<0.05$ compared with $\mathrm{IR} ;{ }^{\mathrm{C} P}<0.05$ compared with $\mathrm{D} 1 ;{ }^{\mathrm{d}} \mathrm{P}<0.05$ compared with D5; ${ }^{\mathrm{P}}<0.05$ compared with $\mathrm{D} 10$.

\section{Histopathological changes}

The histological examination showed minimal lung injury in the $S$ group, and severe injury in the IR, DY, and $Y$ groups. In contrast, lungs from the D1, D5, and D10 groups exhibited mild to moderate injury (in descending order of severity) (Figure 2). The lung injury score was consistent with the histological findings. The score of the S group $(1.5 \pm 0.5)$ was significantly lower than that of all other groups $(P<0.05)$, and those of the Dex-treated groups, D1 (6.0 $\pm 0.8)$, D5 $(4.8 \pm 0.7)$, and D10 groups (2.5 \pm $0.9)$ were significantly lower compared with that of the IR group $(8.5 \pm 0.9)$ (all $P<0.05)$. The lung injury score significantly increased in the yohimbine groups (DY group, $8.1 \pm 0.6$; and $Y$ group, $8.9 \pm 0.8$ ) compared with that of all Dex-treated groups $(P<0.05)$. No significant difference in lung injury score was observed between yohimbine groups and the IR group (Figure 2). 
A

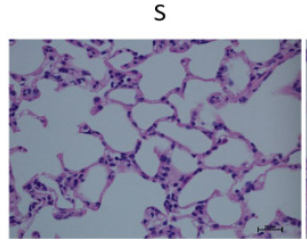

D10

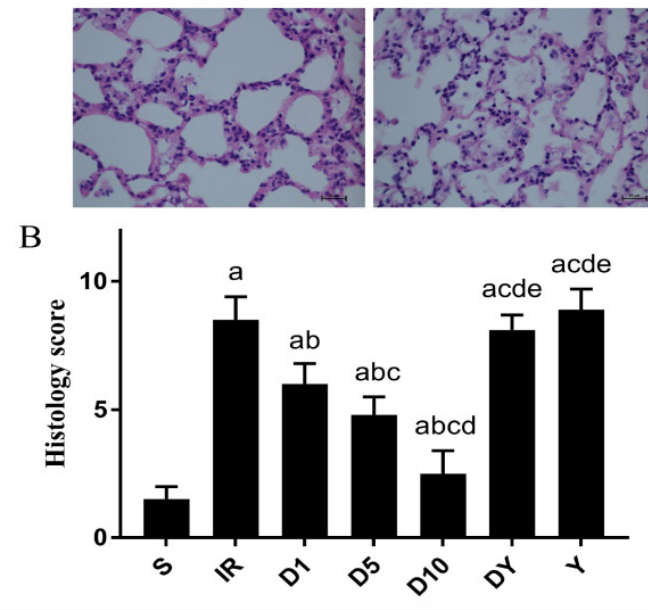

B
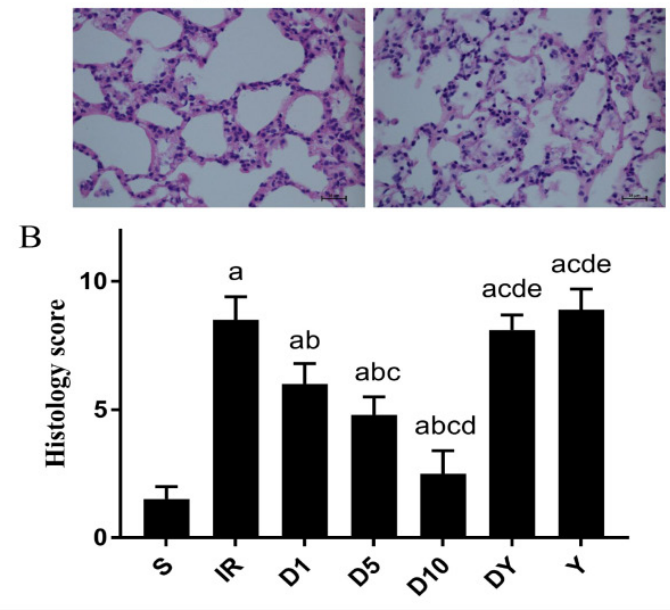

IR

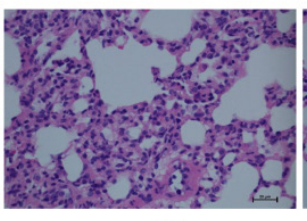

DY

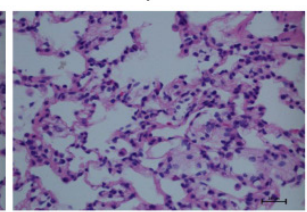

D1

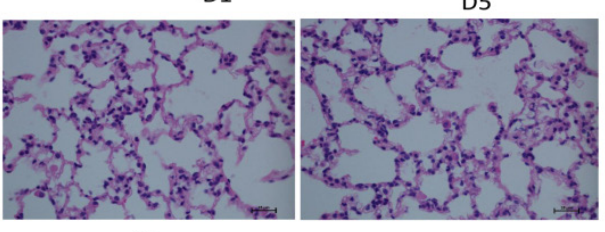

Y

Figure 2 - Microscopic findings from the rat left lung tissues stained with hematoxylin and eosin (magnification, $\mathrm{x} 400)$. The data are presented as the mean \pm standard deviation. S: sham; IR: ischemia-reperfusion; D1: $1 \mathrm{nM}$ dexmedetomidine; D5: $5 \mathrm{nM}$ dexmedetomidine; D10: $10 \mathrm{nM}$ dexmedetomidine; DY: $10 \mathrm{nM}$ dexmedetomidine+1 $\mu \mathrm{M}$ yohimbine; $\mathrm{Y}: 1 \mu \mathrm{M}$ yohimbine. ${ }^{\mathrm{a}} \mathrm{P}<0.05$ compared with $\mathrm{S}$; ${ }^{\mathrm{b} P}<0.05$ compared with $\mathrm{IR}$; ${ }^{\mathrm{C}} \mathrm{P}<0.05$ compared with $\mathrm{D} 1$; ${ }^{\mathrm{d}} \mathrm{P}<0.05$ compared with $\mathrm{D} 5$; ${ }^{\mathrm{e}} \mathrm{P}<0.05$ compared with $\mathrm{D} 10$.

Effects of Dex on the SOD activity and MDA level

The SOD activity in the lung tissue was lower in all the other groups than that in the $\mathrm{S}$ group $(85.8 \pm 4.9 \mathrm{U} / \mathrm{ml})(\mathrm{P}<0.05)$. It rose to $58.4 \pm 4.0 \mathrm{U} / \mathrm{ml}$ in the D1 group, $63.8 \pm 4.8$ $\mathrm{U} / \mathrm{ml}$ in the D5 group, and $69.5 \pm 5.0 \mathrm{U} / \mathrm{ml}$ in the D10 group, compared with that of the IR group $(43.3 \pm 3.9 \mathrm{U} / \mathrm{ml})(\mathrm{P}<0.05)$. This was reversed by yohimbine treatment, where the SOD activity significantly decreased in the yohimbine groups (DY group, $46.6 \pm 4.0 \mathrm{U} / \mathrm{ml}$; and $Y$ group, $42.6 \pm 7.0 \mathrm{U} / \mathrm{ml}$ ) compared with all Dex-treated groups $(P<0.05)$. No significant difference in the SOD activity was observed between yohimbine groups and the IR group (Figure 3A). Conversely, the MDA levels in the lung tissue were significantly higher in all other groups compared with that of the $S$ group $(2.0 \pm 0.3 \mathrm{nmol} / \mathrm{ml})(P<0.05)$. The MDA level significantly decreased following Dex treatment (D1 group, $3.2 \pm 0.3 \mathrm{nmol} / \mathrm{ml}$; D5 group, $2.9 \pm 0.3 \mathrm{nmol} / \mathrm{ml}$; and D10 group, 2.5 $\pm 0.3 \mathrm{nmol} / \mathrm{ml}$ ) compared with that of the IR group $(3.8 \pm 0.2 \mathrm{nmol} / \mathrm{ml})(P<0.05)$. Yohimbine significantly reversed the effect of Dex on the MDA level (DY group, $3.7 \pm 0.3 \mathrm{nmol} / \mathrm{ml}$; and $Y$ group, $4.0 \pm 0.4 \mathrm{nmol} / \mathrm{ml})$ in all Dex-treated groups $(P<0.05)$. The yohimbine and IR groups showed no significant difference in the MDA level (Figure 3B). 
A

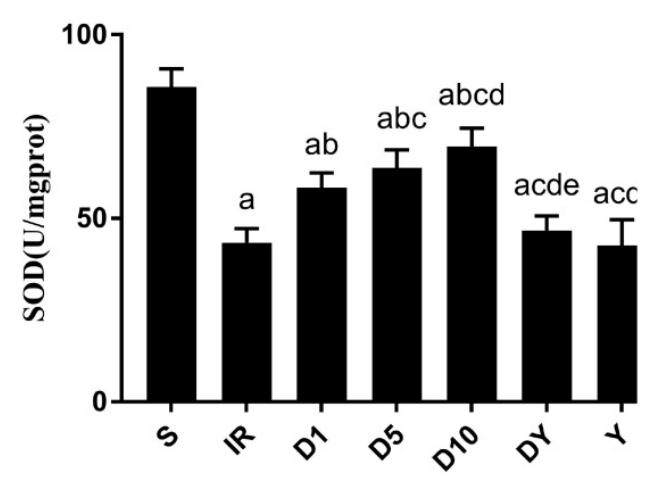

B

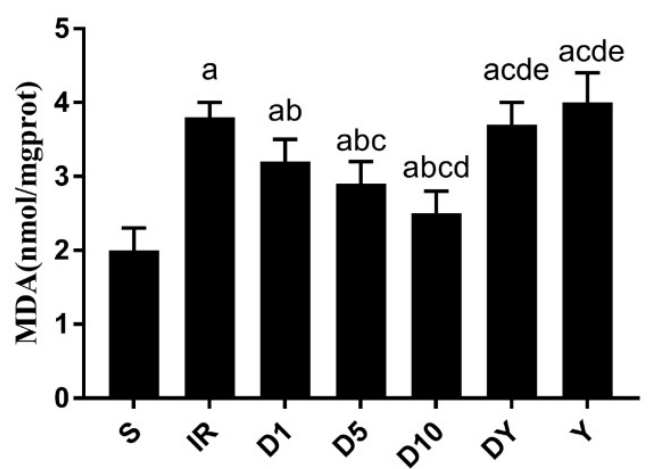

Figure 3 - SOD activity (A) and MDA level (B) in lung tissues isolated from rats of the seven groups. The data are presented as the mean \pm standard deviation. S: sham; IR: ischemia-reperfusion; D1: $1 \mathrm{nM}$ dexmedetomidine; D5: $5 \mathrm{nM}$ dexmedetomidine; D10: $10 \mathrm{nM}$ dexmedetomidine; DY: $10 \mathrm{nM}$ dexmedetomidine $+1 \mu \mathrm{M}$ yohimbine; $\mathrm{Y}: 1 \mu \mathrm{M}$ yohimbine. ${ }^{\mathrm{a} P}<0.05$ compared with $\mathrm{S}$; ${ }^{\mathrm{b}} \mathrm{P}<0.05$ compared with $\mathrm{IR} ;{ }^{\mathrm{C}} \mathrm{P}<0.05$ compared with $\mathrm{D} 1 ;{ }^{\mathrm{d}} \mathrm{P}<0.05$ compared with $\mathrm{D} 5$; ${ }^{\mathrm{e}}<0.05$ compared with $\mathrm{D} 10$.

\section{Effects of Dex on GRP78 and CHOP MRNA and protein levels}

The qPCR analysis demonstrated that the mRNA levels of GRP78 and CHOP in the lung tissue in the $S$ group $(1.1 \pm 0.2$ and 1.0 \pm 0.1 , respectively) were significantly lower compared with that of all other groups $(P<$ 0.05), whereas the GRP78 and CHOP transcript levels were significantly upregulated in the IR group $(2.5 \pm 0.3$ and $3.1 \pm 0.4$, respectively) compared with all Dex-treated groups (D1 group, $1.9 \pm 0.3,2.3 \pm 0.3 ;$ D5 group, $1.7 \pm$ $0.1,2.0 \pm 0.2 ;$ and D10 group, $1.5 \pm 0.1,1.7$ \pm 0.2 , respectively) $(P<0.05)$ (Figure $4 A-B)$. Furthermore, the expression of GRP78 and CHOP at the mRNA levels in the yohimbine groups (DY group, $2.4 \pm 0.3$ and $2.9 \pm 0.3$; and $Y$ group, $2.4 \pm 0.3$ and $3.2 \pm 0.5$, respectively) significantly increased compared with that of all Dex-treated groups. However, no significant difference was observed in GRP78 and CHOP mRNA levels between yohimbine groups and the IR group (Figure 4A-B).
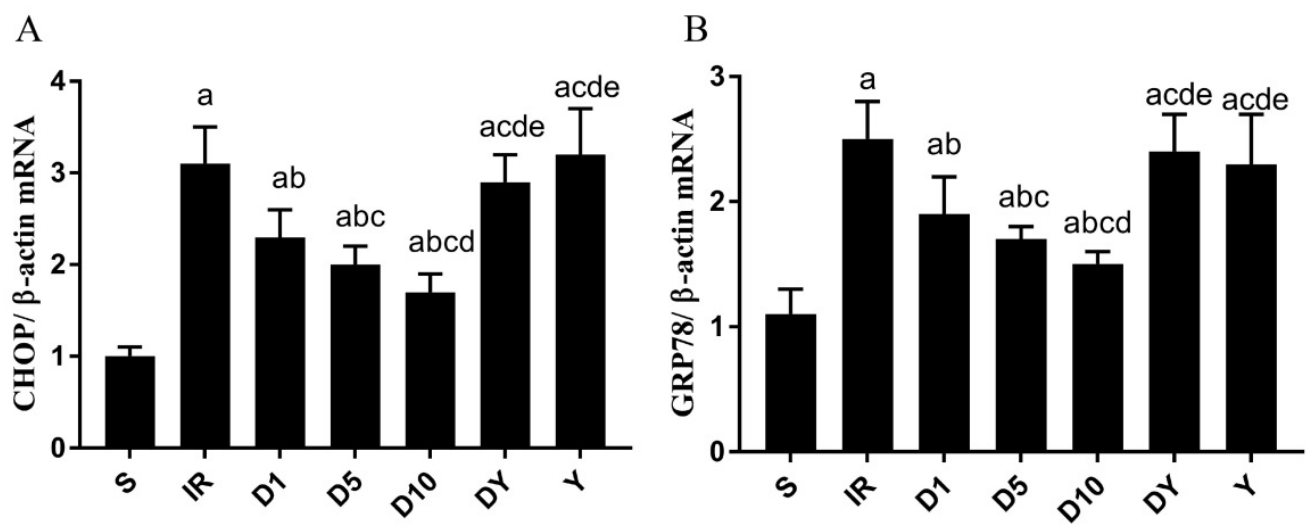

Figure 4 - Expression of GRP78 mRNA (A) and CHOP mRNA (B) in lung tissues isolated from rats of the seven groups. The data are presented as the mean \pm standard deviation. S: sham; IR: ischemia-reperfusion; D1: $1 \mathrm{nM}$ dexmedetomidine; D5: $5 \mathrm{nM}$ dexmedetomidine; D10: $10 \mathrm{nM}$ dexmedetomidine; DY: $10 \mathrm{nM}$ dexmedetomidine $+1 \mu \mathrm{M}$ yohimbine; $\mathrm{Y}: 1 \mu \mathrm{M}$ yohimbine. ${ }^{\mathrm{P}}<0.05$ compared with $\mathrm{S}$; ${ }^{\mathrm{b}} \mathrm{P}<0.05$ compared with $\mathrm{IR}$; ${ }^{\mathrm{C}}<0.05$ compared with $\mathrm{D} 1$; ${ }^{\mathrm{d} P}<0.05$ compared with $\mathrm{D} 5$; ${ }^{\mathrm{eP}}<0.05$ compared with $\mathrm{D} 10$. 
The GRP78 and CHOP expression at the protein level was consistent with the qPCR findings. The western blot results showed that the GRP78 and CHOP protein levels were significantly higher in all the other groups compared with that of the S group $(0.34 \pm$ 0.06 and $0.27 \pm 0.05$, respectively) $(P<0.05)$, whereas the GRP78 and CHOP protein levels were significantly downregulated in the Dextreated groups (D1 group, $1.00 \pm 0.10,0.76 \pm$ 0.08 ; D5 group, $0.81 \pm 0.07,0.57 \pm 0.06$; and D10 group, $0.60 \pm 0.07,0.41 \pm 0.05$, respectively) compared with that of the IR group $(1.16 \pm$ $0.13,0.95 \pm 0.07$, respectively) $(P<0.05)$ (Figure $5)$. Yohimbine reversed the effects of Dex on the GRP78 and CHOP protein levels, in which significantly higher expression of GRP78 and CHOP was observed in the yohimbine groups (DY group, $1.13 \pm 0.09,0.94 \pm 0.06$; and $Y$ group, $1.15 \pm 0.13,0.96 \pm 0.10$, respectively) compared with that of all Dex-treated groups $(P<0.05)$. No significant difference was observed in GRP78 and CHOP protein levels between yohimbine groups and the IR group (Figure 5).

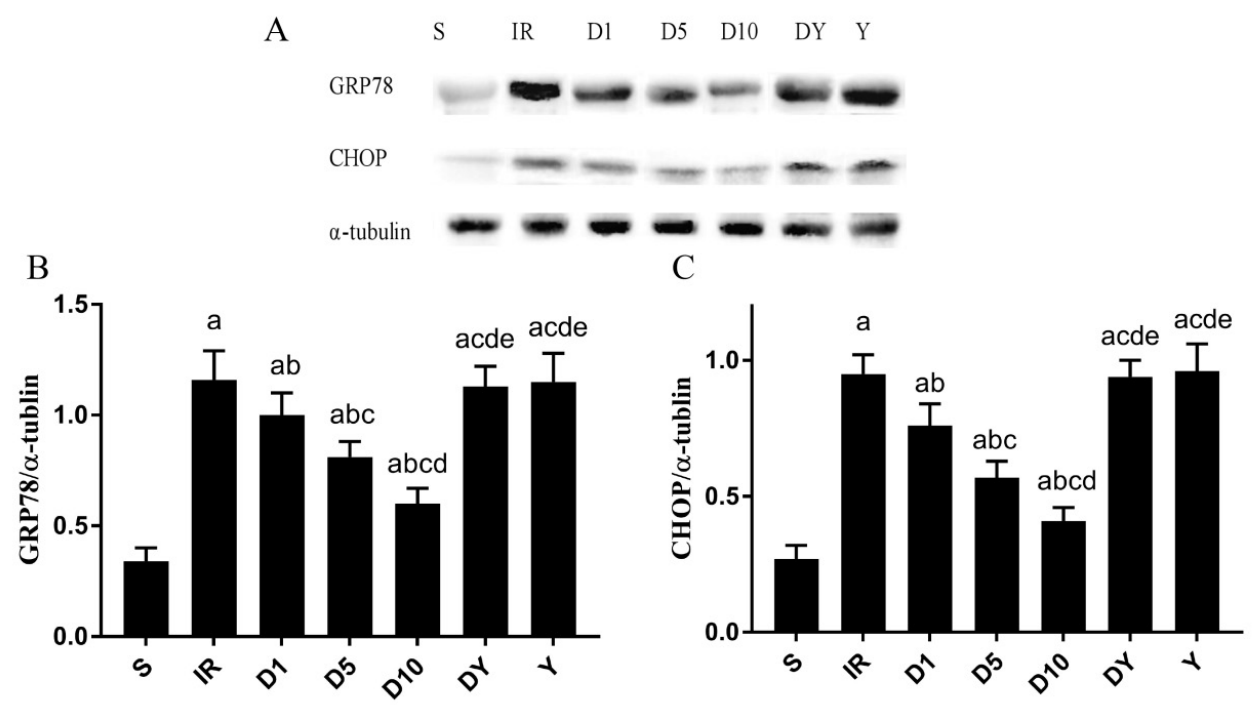

Figure 5 - The protein expression of GRP78 and CHOP in lung tissues isolated from rats of the seven groups. (A) Western blot analysis of GRP78 and CHOP expression; (B) Quantification of GRP78/ $\alpha$-tubulin; and (C) $\mathrm{CHOP} / \alpha$-tubulin. The data are presented as the mean \pm standard deviation. S: sham; IR: ischemia-reperfusion; D1: $1 \mathrm{nM}$ dexmedetomidine; D5: $5 \mathrm{nM}$ dexmedetomidine; D10: $10 \mathrm{nM}$ dexmedetomidine; DY: $10 \mathrm{nM}$ dexmedetomidine $+1 \mu \mathrm{M}$ yohimbine; $\mathrm{Y}: 1 \mu \mathrm{M}$ yohimbine. ${ }^{\mathrm{a}} \mathrm{P}<0.05$ compared with $\mathrm{S}$; ${ }^{\mathrm{b}} \mathrm{P}<0.05$ compared with $\mathrm{IR}$; ${ }^{\mathrm{C}} \mathrm{P}<0.05$ compared with $\mathrm{D} 1$; ${ }^{\mathrm{d}} \mathrm{P}<0.05$ compared with $\mathrm{D} 5$; ${ }^{\mathrm{e}} \mathrm{P}<0.05$ compared with $\mathrm{D} 10$.

\section{Discussion}

LIRI is caused by a sudden temporary impairment of the blood flow to the lung, associated with a robust inflammatory and oxidative stress response to hypoxia, which is further exacerbated by subsequent reperfusion, leading to perturbation of the lung function ${ }^{17}$. In ischemic lung and subsequent re-oxygenation, generation of reactive oxygen species at reperfusion phase initiates a cascade of deleterious cellular responses leading to inflammation, cell death, and acute lung failure ${ }^{2-4}$.

Oxidative stress is one of the known mechanisms leading to $\mathrm{LIRI}^{17}$. SOD is an important antioxidant enzyme, which plays an important role in scavenging oxygen free radicals. Therefore, SOD activity indirectly reflects the antioxidant activity in a tissue ${ }^{22}$, 
whereas MDA is a product of lipid peroxidation, in which its expression level is positively correlated with the generation of oxygen free radicals and reflects the degree of lipid peroxidation ${ }^{23}$. Thus, the SOD activity and MDA level are good indicators of the oxidative stress level. Previous studies have shown decreased SOD activity and increased MDA level in a rabbit LIRI model ${ }^{24}$. In this study, we demonstrated similar trends, a decrease in the SOD activity and increased MDA level in the ex vivo rat lung after ischemia and reperfusion, indicating a high level of oxidative stress after IR.

Furthermore, oxidative stress causes retention of unfolded or misfolded proteins inside the ER lumen, which affects the physiological function of ER that results in $\mathrm{ERS}^{25}$. GRP78 is a molecular chaperone protein, which plays an important role in maintaining ER homeostasis. Under normal conditions, GRP78 is coupled with the ERS receptors to inhibit their activity. When misfolded proteins accumulate in the ER, GRP78 dissociates from the receptors, resulting in the ERS receptors activation, which in turn triggers the UPR ${ }^{26}$. However, when prolonged ERS occurs, cells are unable to restore ER functions through selfregulation, which causes the activation of $\mathrm{CHOP}$ mediated apoptosis to eliminate damaged cells that cannot be repaired promptly ${ }^{27}$. In this study, our results demonstrated that both of the mRNA and protein levels of GRP78 and CHOP were significantly increased in the ex vivo lung with IR injury, suggesting that LIRI led to a higher ERS response. Furthermore, our findings showed that the increased expression of GRP78 and CHOP was rescued by the Dex treatment in a dose-dependent manner. This suggests that Dex inhibited the ERS response through its antioxidant effect, reducing lung injury and protecting lungs against IR injury.

Previous studies have shown effective measures against LIRI such as antioxidant therapy, anti-inflammatory therapy, growth factor therapy, and mesenchymal stem cell therapy ${ }^{28}$. However, all of these studies were performed using animal models. To date, no drug has been clinically proven to have an effective protective effect against LIRI in human. With increasing cases of lung transplant each year ${ }^{29}$, this presses the importance of understanding the mechanisms of LIRI to facilitate the search for effective therapies to prevent and treat perioperative LIRI.

Our findings have shown that ischemiareperfusion downregulated the SOD activity and increased the levels of MDA, GRP78 and CHOP in lung tissues, supporting UPR induced by excessive endoplasmic reticulum stress (ERS) as one of the underlying pathophysiological mechanisms leading to LIRI. Increased expression of GRP78 and CHOP after IR suggests the induction of ER luminal chaperones to promote protein folding and activation of apoptosis, respectively. Furthermore, we demonstrated that treatment with Dex attenuated pulmonary damage and inhibited UPR induced by LIRI, in a dosedependent manner, suggesting that inhibition of ERS activation is involved in the protective mechanism of Dex against LIRI. Furthermore, our results showed that the protective effects of Dex were substantially reversed by the $\alpha_{2}$ receptor antagonist, yohimbine. Thus, this study extends our current understanding of the underlying mechanisms leading to LIRI and provides potential clinical implications of Dex for prevention and treatment of LIRI.

\section{Conclusion}

That unfolded protein response (UPR) may be one of the pathophysiological mechanisms leading to ischemia-reperfusion injury (LIRI) and dexmedetomidine (Dex) conferred its protective effects against LIRI by inhibiting UPR in the ex vivo rat lung model of ischemia-reperfusion injury, suggesting that Dex may be a potential treatment for LIRI. 


\section{References}

1. Granton J. Update of early respiratory failure in the lung transplant recipient. Curr Opin Crit Care. 2006;12(1):19-24. PMID: 16394779.

2. Christie JD, Carby M, Bag R, Corris P, Hertz M, Weill D. Report of the ISHLT working group on primary lung graft dysfunction part ii: definition. A consensus statement of the International Society for Heart and Lung Transplantation. J Heart Lung Transplant. 2005;24(10):1454-9. PMID: 16210116.

3. Dierich $M$, Tecklenburg $A$, Fuehner $T$, Tegtbur U, Welte T, Haverich A, Warnecke $\mathrm{G}$, Gottlieb J. The influence of clinical course after lung transplantation on rehabilitation success. Transplant Int. 2013;26(3):322-30. PMID: 23294442.

4. Porteous MK, Diamond JM, Christie JD. Primary graft dysfunction: lessons learned about the first $72 \mathrm{~h}$ after lung transplantation. Curr Opin Organ Transplant. 2015;20(5):50614. PMID: 26262465.

5. Laubach VE, Sharma AK. Mechanisms of lung ischemia-reperfusion injury. Curr Opin Organ Transplant. 2016;21(3):246-52. PMID: 26945320.

6. Tan JA, Ho KM. Use of dexmedetomidine as a sedative and analgesic agent in critically ill adult patients: a meta-analysis. Intens Care Med. 2010;36(6):926-39. PMID: 20376429.

7. Shi $Q Q$, Wang $H$, Fang $H$. Dose-response and mechanism of protective functions of selective alpha-2 agonist dexmedetomidine on acute lung injury in rats. Saudi Med J. 2012;33(4):375-81. PMID: 22485231.

8. Yagmurdur $\mathrm{H}$, Ozcan N, Dokumaci F, Kilinc K, Yilmaz F, Basar H. Dexmedetomidine reduces the ischemia-reperfusion injury markers during upper extremity surgery with tourniquet. J Hand Surg. 2008;33(6):941-7. PMID: 18656769.

9. Yang CL, Tsai PS, Huang CJ. Effects of dexmedetomidine on regulating pulmonary inflammation in a rat model of ventilatorinduced lung injury. Acta Anaesthesiol Taiwan. 2008;46(4):151-9. PMID: 19097961.

10.Jiang L, Li L, Shen J, Qi Z, Guo L. Effect of dexmedetomidine on lung ischemia-reperfusion injury. Mol Med Rep. 2014;9(2):419-26. PMID: 24345905.

11.Chatterjee S, Nieman GF, Christie JD, Fisher
AB. Shear stress-related mechanosignaling with lung ischemia: lessons from basic research can inform lung transplantation. Am J Physiol Lung Cell Mol Physiol. 2014;307(9):668-80. PMID: 25239915.

12. Osorio F, Lambrecht B, Janssens S. The UPR and lung disease. Semin Immunopathol. 2013;35(3):293-306. PMID: 23536202.

13. Nishitoh $H$. CHOP is a multifunctional transcription factor in the ER stress response. J Biochem. 2012;151(3):217-9. PMID: 22210905.

14.Rozpedek W, Pytel D, Mucha B, Leszczynska $H$, Diehl JA, Majsterek I. The Role of the PERK/elF2 $\alpha /$ ATF4/CHOP signaling pathway in tumor progression during endoplasmic reticulum stress. Curr Mol Med. 2016;16(6):533-44. PMID: 27211800.

15.Endo $M$, Oyadomari $S$, Suga $M$, Mori $M$, Gotoh T. The ER stress pathway involving CHOP is activated in the lungs of LPS-treated mice. J Biochem. 2005;138(4):501-7. PMID: 16272146.

16.Endo $M$, Mori $M$, Akira S, Gotoh T. C/EBP Homologous Protein (CHOP) Is crucial for the induction of caspase-11 and the pathogenesis of lipopolysaccharideinduced inflammation. J Immunol. 2006;176(10):6245-53. PMID: 16670335.

17. Hatachi G, Tsuchiya T, Miyazaki T, Matsumoto K, Yamasaki N, Okita N, Nanashima A, Higami Y, Nagayasu T. The poly (adenosine diphosphate-ribose) polymerase inhibitor PJ34 reduces pulmonary ischemiareperfusion injury in rats. Transplantation. 2014;98(6):618-24. PMID: 25221900.

18.Pêgo-Fernandes PM, Werebe $E$, Cardoso PF, Pazetti R, de Oliveira KA, Soares PR, Jatene FB. Experimental model of isolated lung perfusion in rats: first Brazilian experience using the IL-2 isolated perfused rat or guinea pig lung system. Transplant Proc. 2010;42(2):444-7. PMID: 20304160.

19.Oshima Y, Minami Y, Sakamoto S, Yamasaki K, Mochida S, Funaki K, Moriyama N, Otsuki A, Inagaki Y. Phosphoenolpyruvate administration protects ischemiareperfusion injury in isolated rabbit lungs. J Anesth. 2015;29(4):635-8. PMID: 25603734.

20.Pêgo-Fernandes PM, Werebe EC, Cardoso PF, Pazetti R, Oliveira KA, Soares PR, Jatene FB. Experimental model of isolated lung perfusion in rats: technique and application 
in lung preservation studies. J Bras Pneumol. 2010;36(4):490-3. PMID: 20835597.

21.Kozian A, Schilling $T$, Fredén $F$, Maripuu E, Röcken C, Strang C, Hachenberg T, Hedenstierna G. One-lung ventilation induces hyperperfusion and alveolar damage in the ventilated lung: an experimental study. $\mathrm{Br} J$ Anaesth. 2008;100(4):549-59. PMID: 18308740.

22.Brüne B, Zhou J. Nitric oxide and superoxide: interference with hypoxic signaling. Cardiovasc Res. 2007;75(2):275-82. PMID: 17412315.

23.Fu Z, Liu X, Geng B, Fang L, Tang C. Hydrogen sulfide protects rat lung from ischemiareperfusion injury. Life Sci. 2008;82(2324):1196-202. PMID: 18482739.

24.Tian XX, Wang BL, Cao YZ, Zhong YX, Tu YY, Xiao JB, He QF, Zhai LN. Comparison of protective effects of safflor injection and extract of Ginkgo biloba on lung ischemia/ reperfusion injury in rabbits. Chin J Integr Med. 2015;21(3):229-33. PMID: 24142260.

25.Pahl HL. Signal transduction from the endoplasmic reticulum to the cell nucleus. Physiol Rev. 1999;79(3):683-701. PMID:
10390516.

26.Zhu $H$, Fan $Y$, Sun $H$, Chen L, Man X. Curcumin inhibits endoplasmic reticulum stress induced by cerebral ischemiareperfusion injury in rats. Exp Ther Med. 2017;14(5):4047-52. PMID: 29067098.

27.Kong FJ, Ma LL, Guo JJ, Xu LH, Li Y, Qu S. Endoplasmic reticulum stress/autophagy pathway is involved in diabetes-induced neuronal apoptosis and cognitive decline in mice. Clin Sci (Lon). 2017. [Epub ahead of print]. PMID:29212786.

28.Tian W, Liu Y, Zhang B, Dai X, Li G, Li X, Zhang $Z$, Du C, Wang $H$. Infusion of mesenchymal stem cells protects lung transplants from cold ischemia-reperfusion injury in mice. Lung. 2015;193(1):85-95. PMID: 25344633.

29.Lund LH, Edwards LB, Kucheryavaya AY, Benden C, Dipchand AI, GoldfarbS, Levvey BJ, Meiser B, Rossano JW, Yusen RD. The registry of the International Society for heart and lung transplantation: Thirty-second official adult heart transplantation report--2015; Focus theme: early graft failure. J Heart Lung Transplant. 2015;34(10):1244-54. PMID: 26454738.

\section{Correspondence:}

Zhiping Wang

Department of Anesthesiology, Wuxi People's Hospital

№ 299 Qingyang Lu

Jiangsu China

Wangzhipcxx@163.com

Received: Sep 15, 2017

Review: Nov 16, 2017

Accepted: Dec 19, 2017
Conflict of interest: none

Financial source: Wuxi City Science and Technology Development Project (grant numbers CSE31N1615) 